\title{
GEOGRAFIA DA EDUCAÇÃO DO CAMPO NO TRIÂNGULO MINEIRO
}

\author{
Ricardo Araujo Leite ${ }^{\mathrm{i}}$ \\ Marcelo Cervo Chelotti ${ }^{\text {ii }}$
}

\section{RESUMO}

O presente artigo tem por objetivo refletir sobre os desafios da educação do campo no Triângulo Mineiro, região que nas últimas décadas caracterizou-se por uma intensa territorialização do agronegócio, ao mesmo tempo em que avançaram as reivindicações dos movimentos sociais do campo. Portanto, o caráter modernizador tornou invisível a demanda por outra educação, ou seja, uma educação do campo em consonância com os anseios da população rural.

Palavras-Chave: Geografia Agrária; Educação do Campo; Triângulo Mineiro.

\section{THE GEOGRAPHY OF THE EDUCATION OF THE FIELD IN THE MINAS GERAIS TRIANGLE}

\begin{abstract}
The present article has for objective to reflect on the challenges of the education of the field in the Triângulo Mineiro of Minas Gerais, region that in the last few decades was characterized for an intense territorialization of the agribusiness, at the same time where they had advanced the claims of the social movements of the field. Therefore, the modernized character became invisible the demand for another education, that is, an education of the field in accord with the yearnings of the agricultural population. Keywords: Agrarian geography. Education of the Field. Triângulo Mineiro.
\end{abstract}

\section{Introdução}

O presente artigo é fruto das reflexões e experiências desenvolvidas no decorrer dos últimos quatro anos durante a execução do projeto de extensão "A geografia vai ao acampamento" (Etapa I em 2009, Etapa II em 2010, Etapa III em 2011 e 2012), em que foi possível constatar a partir das visitas em diversos acampamentos de trabalhadores rurais sem terra, as reais condições do ensino-aprendizagem das crianças residentes nesses locais. Dentro das competências associadas ao ensino de Geografia, foram propostas atividades que puderam ser desenvolvidas pelos alunos, exercitando assim a capacidade de aprendizado, fixação e execução do que lhes é proposto dentro do conteúdo de ensino fundamental. Durante as intervenções realizadas nos acampamentos, constatou-se que a metodologia urbana de ensino não se encaixa na realidade desses sujeitos. Logo, é fundamental continuar refletindo sobre a necessidade da construção de metodologias de ensino-aprendizagem em consonância com a realidade do lugar, e a luz das orientações e diretrizes da Educação do Campo.

A partir do conhecimento da realidade vivenciada pelos indivíduos acampados, principalmente pelas crianças em idade escolar, o presente projeto de extensão tem possibilitado ao futuro egresso da Universidade Federal de Uberlândia, em especial os licenciados, uma maior compreensão da atual complexidade da sociedade contemporânea, 
além da aproximação universidade/comunidade, fortalecendo os três pilares da instituição: ensino, pesquisa e extensão.

Sendo assim, na primeira parte do ensaio apresenta-se uma contextualização sobre a discussão envolvendo a educação rural e a educação do campo, e na segunda parte destacase o papel conservador da modernização da agricultura e a questão dos movimentos sociais no campo na região do Triângulo Mineiro. Contextualiza-se também, a questão da latência e pertinência da discussão sobre a educação do campo na região, em que o processo de modernização da agricultura ao mesmo tempo em que possibilitou a territorialização do capital no campo, também provocou a territorialização dos movimentos sociais.

\section{As políticas públicas de educação rural à educação do campo}

No Brasil, os projetos elaborados pelo governo para a educação da população rural sempre tiveram entre os seus principais objetivos: controlar a população camponesa, evitando que ela abandonasse o campo e migrasse para a cidade ou a capacitação técnica necessária para a modernização da agricultura. Esse processo pode ser verificado ainda na "República Velha" quando as atenções se voltaram para educação rural a fim de evitar a forte corrente migratória dos camponeses para as cidades.

[...] Concomitante explodia a ideologia do colonialismo que, ao defender as virtudes do campo e da vida campesina mascarava sua preocupação maior: esvaziamento populacional das áreas rurais, enfraquecimento social e político do patriarcalismo e forte oposição ao movimento progressista urbano, isso principalmente por parte dos agroexportadores, mas o ruralismo contou também com o apoio de alguns segmentos das elites urbanas, que viam na fixação do homem no campo uma maneira de evitar a exploração de problemas sociais nos centros citados. (LEITE, 2002, p. 28-29)

Na década de 1940 conforme Ribeiro (2010) "a indústria estadunidense de produtos agropecuários (máquinas, adubos, defensivos agrícolas) se interessaram pela educação rural no Brasil", esse interesse partiu da necessidade de se abrir novos mercados para esses produtos e se deu de uma forma que impediu o desenvolvimento de indústrias nacionais nessa área, a materialização desse interesse segundo ribeiro se deu pela criação da Comissão Brasileira Americana de Educação das Populações Rurais (Cbar), em 1945 e se manteve nas décadas de 1960 e 1970. Paralelamente era oferecida a uma pequena parcela da população rural, uma educação técnica, voltada para o treinamento de mão-de-obra e para a modernização da agricultura seguindo modelos estadunidenses que pretendiam criar um mercado para seus produtos agrícolas sob o seu modelo de agricultura.

Dentro dessa perspectiva também podemos analisar a criação da Companhia Nacional de Educação Rural (CNER) e o Serviço Social Rural (SSR) na década de 1950, que seguiram modelos indicados pelos EUA, como já havia ocorrido com a ACAR/EMATER (Associação de Crédito e Assistência Rural/Empresa Brasileira de Extensão Rural).

[...] Centrada na ideologia do desenvolvimento comunitário, a modernização do campo nada mais foi do que a internacionalização da economia brasileira aos interesses monopolistas, e a CNER, ao realizar seu trabalho educativo, desconsiderou as contradições naturais dos grupos campesinos, ou mesmo seus elementos integrativos, quer políticos sociais ou culturais. Além disso, as lutas ou reivindicação das minorias rurais 
ficaram obscurecidas, sucumbido frente às expressões comunitárias repassadas pela educação/informação veiculadas na campanha. (LEITE, 2002, p. 37)

Essas políticas trouxeram para o país uma educação tecnicista que não levava em consideração os saberes da população rural e aceleraram a modernização da agricultura, expropriando grande parte dos trabalhadores e produtores rurais que não tiveram acesso a essa modernização. Esse processo também impediu que o país desenvolvesse indústrias próprias para o setor agrário que levasse em conta as necessidades do seu desenvolvimento.

[...] Com isso e fácil deduzir que as políticas sociais destinadas ás populações camponesas, em particular a educação, tiveram maior incremento e volume de recursos quando havia, por parte dos sujeitos do capital, interesses ligados á expropriação da terra e á conseguinte proletarização dos agricultores, combinada com a implementação de uma produção agrícola geradora de dependência científica e tecnológica da parte dos trabalhadores do campo. A educação formadora tanto de uma força de trabalho disciplinada quanto de consumidores dos produtos agropecuários, agindo, nesse sentido, para eliminar os saberes acumulados pela experiência sobre o trabalho com a terra (RIBEIRO, 2010, p. 172)

Na década de 1960 acontece no Brasil às primeiras experiências da pedagogia da alternância, modelo de ensino criado na França que se espalhou pelo mundo, ele se destaca por criar um modelo de ensino que uni espaço rural, escolar e familiar sob um projeto que alterna as lições familiares aprendidas no convívio com a família, comunidade e as lições escolares.

Esse modelo logo se espalhou por todo o país alcançando um grande numero de alunos. Conforme Dias (2006) o objetivo da pedagogia da alternância é a formação integral do jovem do campo no aspecto intelectual e profissional, enfatizando a iniciativa, a criatividade individual, o trabalho em equipe, o senso de responsabilidade, de cooperação e de solidariedade. Esse modelo chegou ao Brasil principalmente na forma de Casas Famílias Rurais (CRFs) criado na França em 1935 e Escolas Famílias Agrícolas (EFAs) criado na Itália entre 1961 e 1962.

Já no âmbito da legislação no país se destacam três leis: a Lei de Diretrizes e Bases (LDB) de 1961 que deixou a educação rural sob os cuidados de municípios falidos e sem capacitação; A Lei 5.692, de 1971, que apenas regulamentou a criação da oitava série e o aumento do ensino técnico; e a atual LDB (criada em 1996) que se destaca por conter em seu artigo 28 novas adaptações necessárias para se adequar às singularidades da população rural, destacando:

I - conteúdos curriculares e metodologias apropriadas às reais necessidades e interesses dos alunos da zona rural; II - organização escolar própria, incluindo adequação calendário escolar às fases do ciclo agrícola e às condições climáticas; III - adequação à natureza do trabalho na zona rural. (BRASIL, Lei 9394/1996).

Essa última LDB é um avanço do III Plano Setorial da Educação, Cultura e Desporto (1980-85). Ela contém todos os avanços políticos em relação à educação no campo, porém, não está sendo cumprida principalmente pela falta de recursos destinada à educação e o baixo comprometimento dos governos com a população camponesa. 
Em 16 abril de 1998 em decorrência do alto índice de analfabetismo e o baixo índice de escolarização dos beneficiários do programa de reforma agrária foi instituído pelo então Ministério Extraordinário de Política Fundiária, atual Ministério do Desenvolvimento Agrário o Programa Nacional de Educação na Reforma Agrária (PRONERA), que conforme Ribeiro (2010) "de 2003 a 2006 permitiu o acesso à escolarização de 247.249 jovens e adultos e capacitaram 1016 profissionais das ciências agrárias para atuarem na assistência técnica aos assentados". Esse programa foi uma das tentativas do governo para tentar sanar os problemas da Educação do Campo que alcançou bons resultados, porém não cobriu a demanda do movimento.

Para melhorar o ensino das crianças, jovens e adultos do movimento e superar os problemas históricos da Educação do Campo, o MST cria em 1996 a primeira Escola Itinerante no Rio Grande do Sul.

[...] Entre os motivos que levaram os trabalhadores rurais sem terra vinculados ao MST a se organizarem na luta pela escola itinerante, destacam-se as dificuldades de acesso á escola convencional por estarem acampados em áreas rurais, geralmente longe das instituições educativas formais e também o questionamento da função social da escola convencional que historicamente tem estado descomprometida com as questões referentes ás desigualdades sociais, econômicas e culturais, e, portanto, desvinculada do projeto Sem Terra. (MEURER; DAVID, 2008, p.46)

A criação da Escola Itinerante foi motivada principalmente pelas reivindicações dos alunos que viam na educação um meio de se inserir no movimento de forma mais capacitada, das famílias e dos professores preocupados com o futuro das crianças dos acampamentos. Estas pessoas enfrentavam problemas para chegar até as escolas devido à distância em relação ao acampamento e a falta de um transporte adequado e eficaz, bem como o preconceito por parte dos colegas e professores que não entendiam a ideologia do movimento e por estarem em constante deslocamento não conseguiam se matricular nas escolas convencionais ou não conseguiam o tempo adequado numa mesma escola para se adaptarem ao conteúdo.

[...] As famílias sem-terra mobilizaram-se (e mobilizam-se) pelo direito à escola e pela possibilidade de uma escola que fizesse a diferença ou tivesse realmente sentido em sua vida presente e futura (preocupação com os filhos). As primeiras a se mobilizar, lá no início na década de 80 , foram às mães e professores, depois os pais e algumas lideranças do movimento; aos poucos as crianças vão tomando também lugar, e algumas vezes á frente, nas ações necessárias para garantir sua própria escola, seja nos assentamentos já conquistados, seja ainda nos acampamentos. Assim nasceu o trabalho com educação escolar no MST. (CALDART, 2003, p.62)

Em 2009 após 13 anos de legalização, o governo do estado do Rio Grande do Sul pôs fim à Escola Itinerante do MST respondendo uma medida do Ministério Público Estadual, o que foi para as lideranças uma tentativa clara de enfraquecer o movimento, colocando barreiras para o seu desenvolvimento. Conforme uma pesquisa do Instituto Nacional de Estudo e Pesquisas Educacionais (INEP) - SECAD (2007) os principais obstáculos para uma educação de qualidade no campo são:

- Insuficiência e precariedade das instalações físicas da maioria das escolas; 
- Dificuldades de acesso dos professores e alunos às escolas, em razão da falta de um sistema adequado de transporte escolar;

- Falta de professores habilitados e efetivos, o que provoca constante rotatividade;

- Falta de conhecimento especializado sobre políticas de educação básica para o meio rural, com currículos inadequados que privilegiam uma visão urbana de educação e desenvolvimento;

- Ausência de assistência pedagógica e supervisão escolar nas escolas rurais;

- Predomínio de classes multisseriadas com educação de baixa qualidade;

- Falta de atualização das propostas pedagógicas das escolas rurais;

- Baixo desempenho escolar dos alunos e elevadas taxas de distorção idade-série;

- Baixos salários e sobrecargas de trabalho dos professores, quando comparados com os que atuam na zona urbana;

- Necessidade de reavaliação das políticas de nucleação das escolas e de implementação de calendário escolar adequado às necessidades do meio rural. (BRASIL, 2007, p. 18)

Para tentar sanar esses problemas e atualizar a LDB de 1996 (que nunca foi posta em prática) o governo lança em novembro de 2010 o decreto presidencial 7.352 que utiliza as definições do Instituto Brasileiro de Geografia e Estatística - IBGE para delimitar como Escola do Campo "aquela situada em área rural, ou situada em área urbana, desde que atenda predominantemente a populações do campo" que seria aos "agricultores familiares, os extrativistas, os pescadores artesanais, os ribeirinhos, os assentados e acampados da reforma agrária, os trabalhadores assalariados rurais, os quilombolas, os caiçaras, os povos da floresta, os caboclos e outros que produzam suas condições materiais de existência a partir do trabalho no meio rural". Essas definições servem para dar base para os artigos deste decreto delimitando o público alvo para receber essas políticas educacionais.

Entre os principais pontos destaca-se como necessário para a Educação do Campo, a formação de profissionais capacitados para atender essa população. Além da estruturação das escolas adequando-as às novas condições tecnológicas de ensino e prática aliadas a modelos pedagógicos formulados para o campo (sugerindo a pedagogia da alternância), adequação do plano pedagógico e do calendário escolar às peculiaridades do camponês e a formação de alianças com os estados, municípios e universidades para melhorar as condições de infraestrutura e formação continuada dos profissionais.

$\S$ 4o A educação do campo concretizar-se-á mediante a oferta de formação inicial e continuada de profissionais da educação, a garantia de condições de infraestrutura e transporte escolar, bem como de materiais e livros didáticos, equipamentos, laboratórios, biblioteca e áreas de lazer e desporto adequados ao projeto político-pedagógico e em conformidade com a realidade local e a diversidade das populações do campo. (DECRETO $\mathrm{N}^{\mathrm{o}}$ 7.352, de 4 de novembro de 2010).

A partir das novas normativas sobre Educação do Campo, reivindicações dos movimentos sociais, e dos pesquisadores da área, o Governo do estado de Minas Gerais abriu um espaço maior para o dialogo sobre o assunto com a criação do Grupo de Trabalho Educação do Campo, que divulga suas discussões e resultados dentro do portal www.educacao.mg.gov.br/gtcampo. Esse espaço põe em evidencia a importância e latência 
da discussão sobre a construção de projetos educacionais em consonância com os anseios das populações rurais.

\section{Modernização do campo, movimentos sociais e escolas rurais no Triângulo Mineiro}

O Triângulo Mineiro (mapa 1) localiza-se na porção oeste de Minas Gerais, ocupado inicialmente para criação extensiva de gado em grandes latifúndios e para a agricultura de subsistência próxima a cursos d'água em áreas de veredas. A sua economia desenvolveu-se graças a sua posição estratégica permitindo a região aproveitar a rede de transportes da Capital Federal e sua proximidade com o estado de São Paulo. Conforme a afirmação de Pessôa (1982) "um fator que contribuiu para o desenvolvimento do Triângulo Mineiro foi a sua proximidade com o estado de São Paulo isto lhe proporcionou facilidades de comércio, de capital, de mão de obra e de toda experiência paulista para o desenvolvimento".

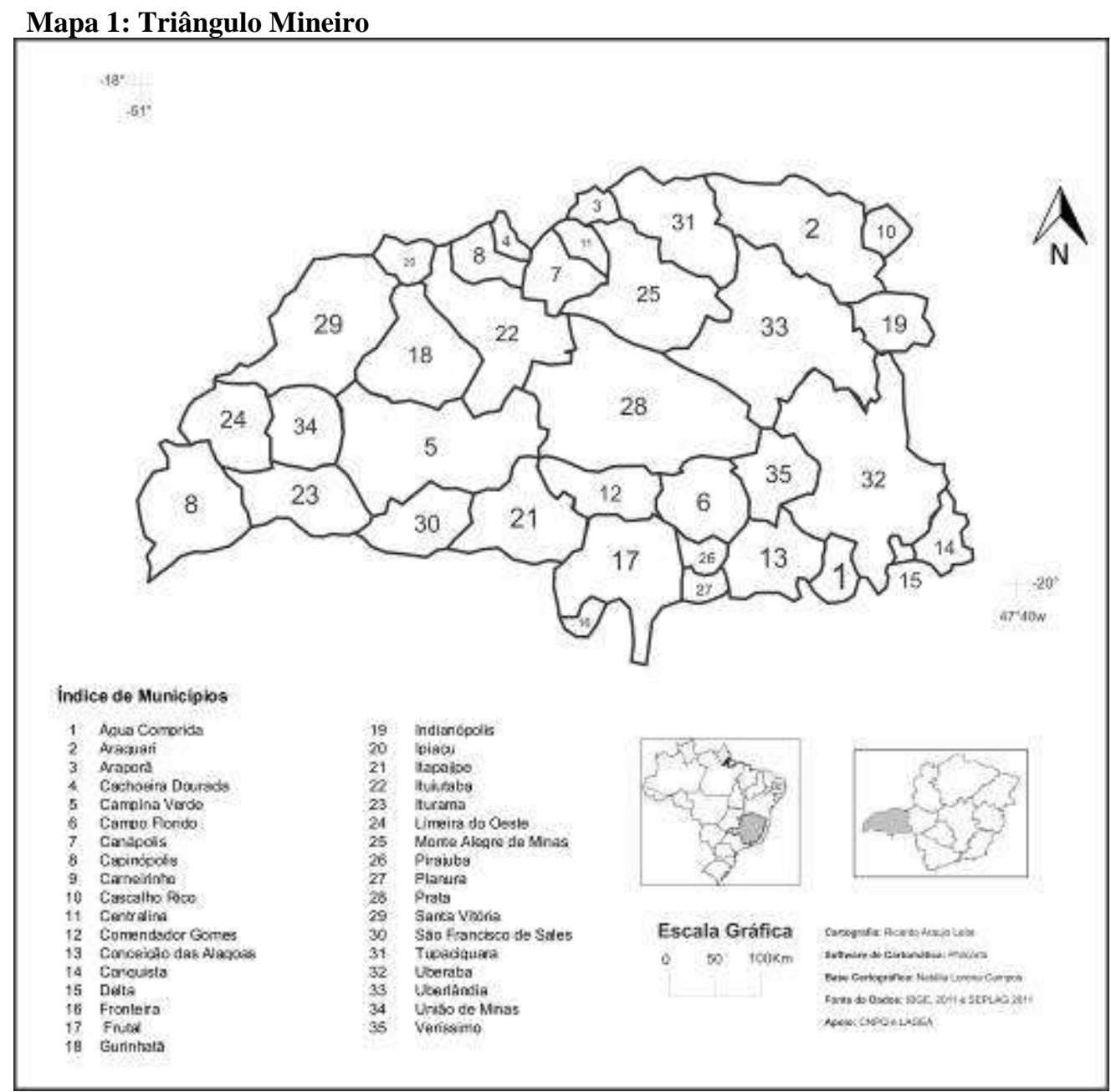

Fonte: IBGE, 2011 e SEPLAG, 2011

A modernização da agricultura segue os modelos traçados no governo militar baseando-se na importação de tecnologias e na criação de programas de crédito rural e 
projetos de colonização. Junto a esses modelos a região sofreu também um intenso processo de industrialização, que na agricultura significou uma troca de cultivos tradicionais por cultivos industriais, que em um primeiro momento foram soja, algodão e amendoim. No momento atual está acontecendo á inserção do cultivo da cana de açúcar em larga escala para atender o setor sucroenergético.

O aumento do capital no campo provocou grandes impactos para os trabalhadores rurais, que excluídos do processo de modernização tiveram de migrar para as cidades. Destacam-se ainda as más condições de vida no campo que não favoreciam os camponeses da mesma forma que aos latifundiários. Como destaca Pessôa (1988), "as condições deficitárias no setor de educação e médicas-sanitárias", mazelas essas que permanecem ate hoje no campo de todo o país, também foram responsáveis pela exclusão dos pequenos agricultores ao acesso aos meios de produção e qualidade de vida.

[...] Com isso, a renda do produtor rural, sobretudo do pequeno, mesmo nas regiões de agricultura mais desenvolvidas se encontra pressionada. Principalmente, porque esse agricultor necessita comprar insumos agrícolas num mercado oligopolista, onde não há controle maior dos preços que vão afetar diretamente os custos do agricultor é obrigado a vender seus produtos em mercados chamados monopsônicos, ou seja, onde há relativamente poucos compradores. (PESSÔA, 1988 p. 6).

Contudo, e de fácil percepção que esse desenvolvimento capitalista excluiu a maior parte da população e continua beneficiando os grandes proprietários de terras. Logo, a consequência é a concentração de terras na região.

[...] O deslocamento da produção de commodities rurais e das agroindústrias para as áreas de cerrados implica na produção de novos espaços dentro dos quais a produção capitalista se expande, trazem profundas consequências como a exploração da força de trabalho e para o meio ambiente (CLEPS JUNIOR, 1998 p. 254).

Nesse contexto, fica claro que o sistema dominante exerce uma força contrária à manutenção da pequena propriedade. As más condições de vida e de produção do pequeno agricultor e dos trabalhadores rurais na região fizeram emergir diversos movimentos sociais de luta pela terra que trazem consigo a luta por uma melhor condição de vida dentro de sua cultura, reivindicando também uma educação apropriada.

Uma maneira de compreender essa mobilização é analisando o gráfico 1 que mostra o número de ocupações no Triângulo Mineiro de 1990 a 2011. 
Gráfico 1: Triângulo Mineiro - número de ocupações por municípios no período 1990-2011

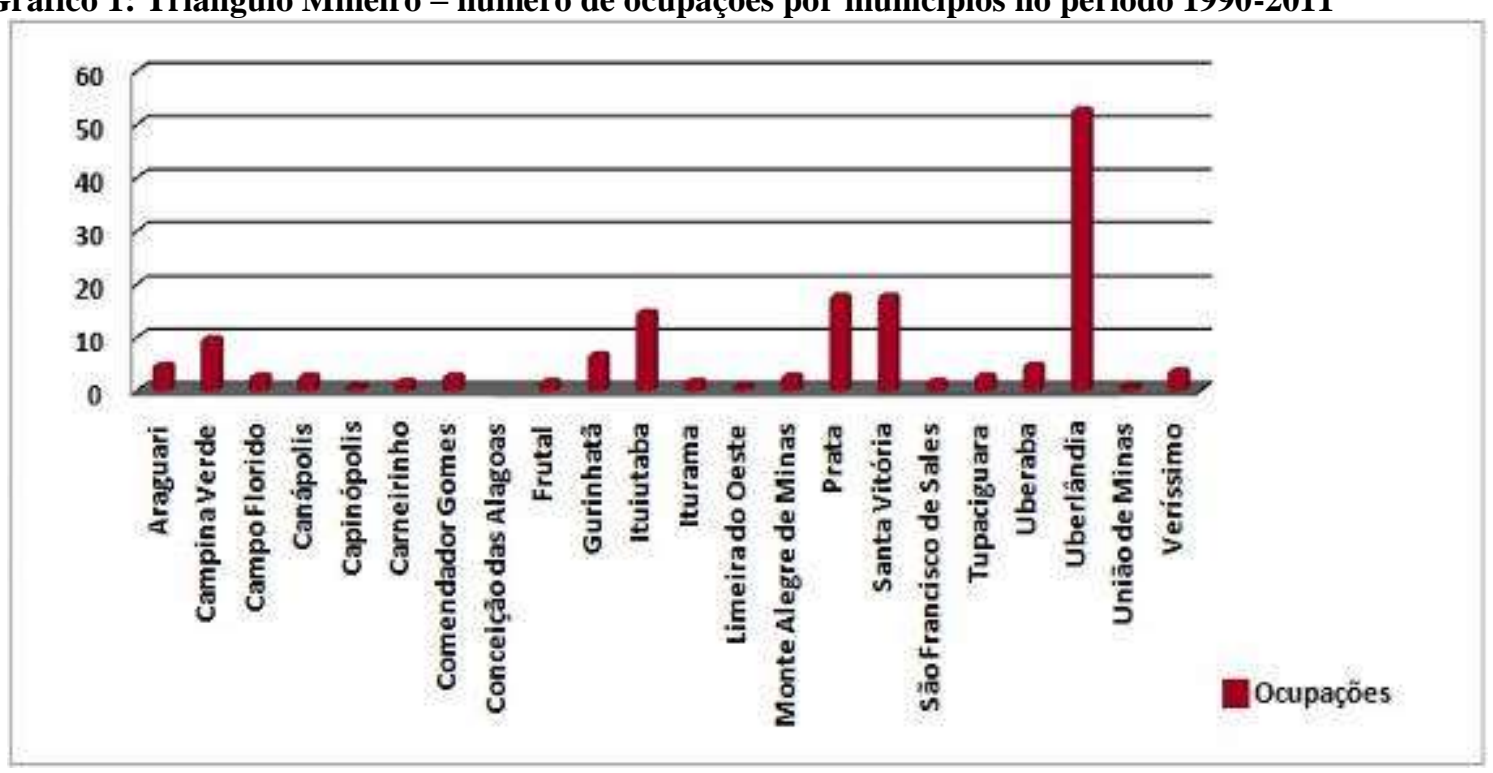

Fonte: Relatório DATALUTA (2011)

Org. LEITE, R. A. (2013)

Os dados demonstram que o campo da região está repleto de lutas que estão representadas pelos acampamentos e assentamentos (gráfico 2) da reforma agrária, sendo que cada um desses gráficos relatam uma luta pela democratização do campo. O município de Uberlândia se destaca nesse ponto sendo um grande pólo das reivindicações em razão da sua importância regional e do seu alto nível de modernização e industrialização da agricultura, sendo também um dos municípios com maior população rural.

Gráfico 2: Triângulo Mineiro - assentamentos por município no período 1986-2011

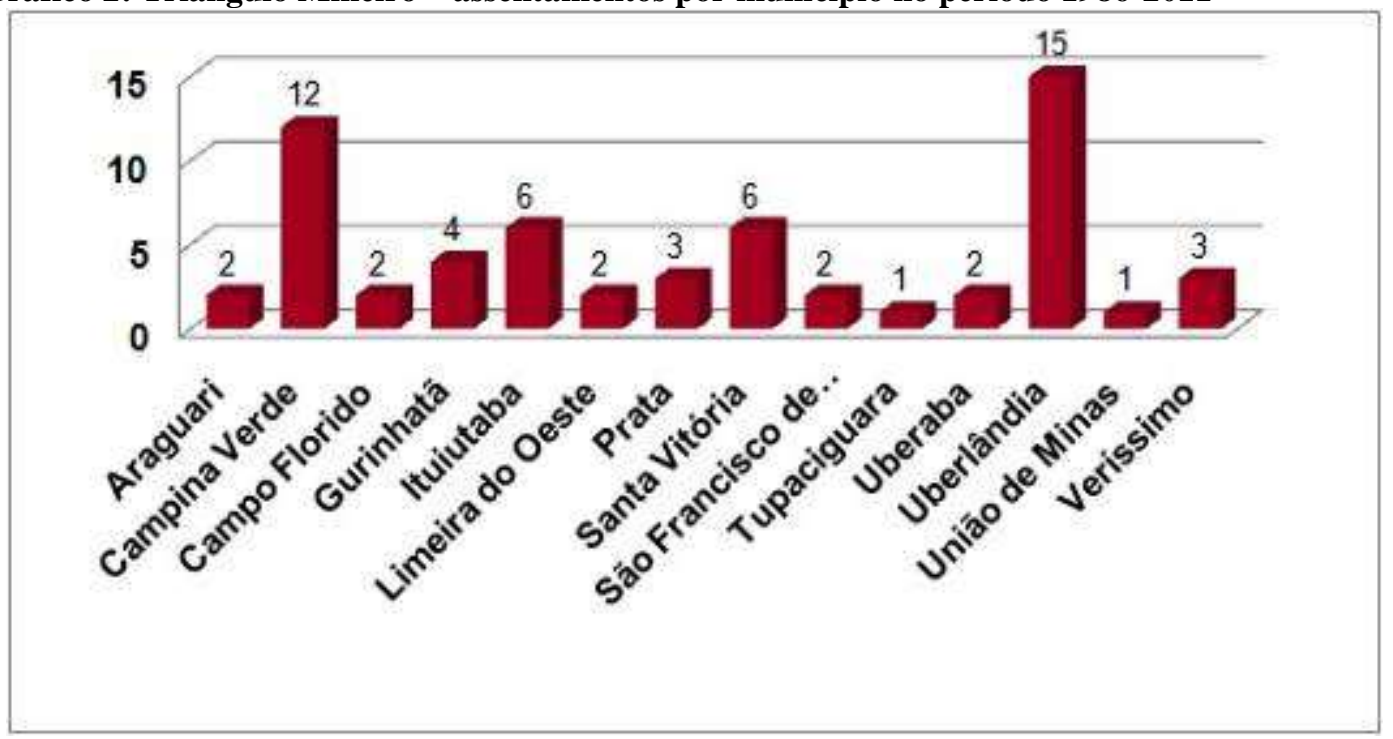

Fonte: Relatório DATALUTA (2011)

Org. LEITE, R. A.(2013)

Nesse meio encontram-se diversos alunos residentes em acampamentos e assentamentos da reforma agrária que necessitam de uma educação que os acompanhe nas andanças dos acampamentos. Respeitando a sua cultura e de suas famílias, preparando-os para desenvolverem suas atividades da melhor forma possível dentro dos assentamentos, dando a eles condições de melhorar as suas vidas e a dos seus pais com a educação recebida na escola. 
Conforme dados do censo escolar de 2010 do Instituto Nacional de Estudos e Pesquisas Educacionais (INEP) foram matriculadas em 2011, 9.439 crianças no ensino fundamental, o que demonstra que existe uma significativa demanda (Mapa 2) para que seja implementado nessa região um modelo de Educação do Campo conforme está escrito em nossas leis e diretrizes.

Mapa 3: Triângulo Mineiro: população e escolas rurais

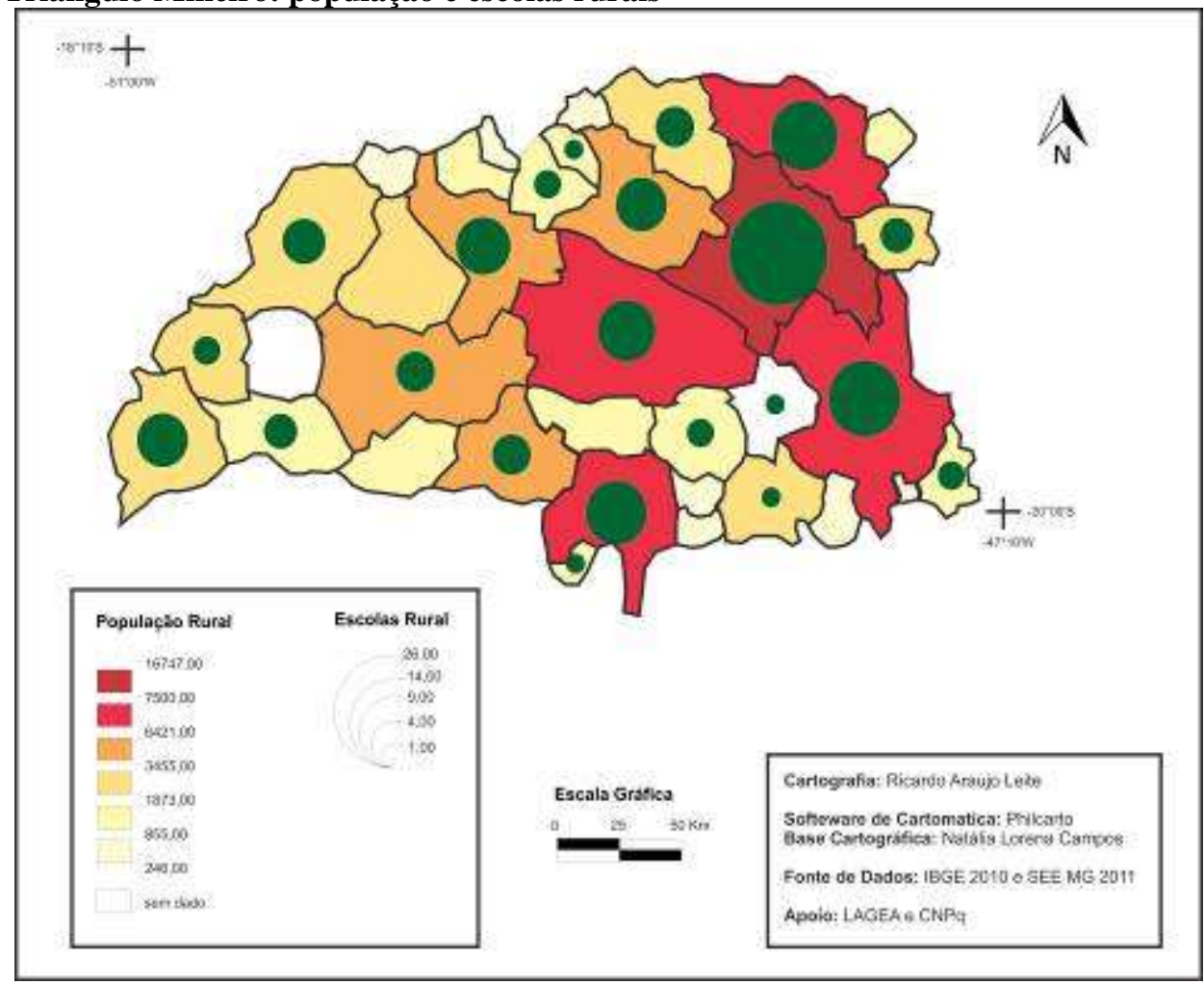

Fonte: SEPLAG, 2011

Conforme dados do mapa 3, verifica-se um grande contingente de pessoas residindo no campo do Triângulo Mineiro, bem como diversas escolas no meio rural (com destaque na tabela para as escolas do ensino fundamental) que atendem a essa população.

A partir dessas análises podemos perceber que o campo do Triângulo Mineiro tem uma grande importância para a economia, e está repleto de contradições sociais e pessoas dispostas a lutar para melhorá-las. Através da educação e do trabalho, esses dados demonstram que essa região é um lugar extremamente adequado para o modelo de educação que defendemos.

A união dos filhos dos assentados, acampados e também dos agricultores familiares que persistem na região formam um grande contingente de estudantes que se enquadram no público alvo da Educação do Campo conforme estipulado pela Lei 9394 de 1996 e pelo decreto 7.352 de 2010. É de grande relevância que esse ensino esteja respaldado pelo modo de produção dessas famílias, para que seja preservada a sua cultura, bem como garantida da segurança alimentar.

Entre todos esses municípios se destacam Uberlândia com 16.747 pessoas no campo, Frutal com 7.379, Araguari 7.218 e Prata com 6.421. Sozinho o contingente da maioria desses é maior que o de muitos municípios da região, o que demonstra que ainda existe muita vida no campo, e que há necessidade de uma reformulação nas políticas públicas. Podemos identificar ainda que diversos municípios menores tem a maioria de sua 
população residindo em áreas urbanizadas, o que é um fato, mas devemos considerar ainda que a maior parte dessas pessoas reproduzem suas vidas na zona rural, nas atividades de lazer, trabalho e no convívio em família.

\section{Considerações Finais}

A educação que vigora atualmente dentro do território rural do país, é de caráter urbanicista, isto é, as aulas ministradas nas escolas rurais funcionam por meio da imposição de um conteúdo ocasionalmente inadequado à realidade do campesinato que, por sua vez, têm suas especificidades e por serem fundamentalmente distintas das peculiaridades urbanas, faz-se necessário que nas instituições de ensino, classificadas como rurais, a educação seja algo voltado para os anseios do cidadão do campo.

Hoje, a área rural do município de Uberlândia conta com 16 mil pessoas, ou seja, fica clara a existência de um significativo contingente de habitantes neste espaço. Esse fato vem subsidiar a discussão acerca da necessidade de se construir um cidadão camponês que saiba ser crítico e assim possa lutar por seus mais variados desejos dentro do território em que vive, imprimindo diferentes relações, movimentando a dinâmica do rural. Dessa maneira, a ciência geográfica, dentro de suas competências, apresenta as falhas do que diz respeito às políticas públicas governamentais que, por hora, não estão conseguindo suprir as necessidades do camponês.

Os dados parciais aqui apresentados demonstram que existe demanda de alunos no campo no Triângulo Mineiro que se enquadra na proposta dos movimentos sociais, e que foram promulgadas pelo Governo Federal por meio das leis e decretos que foram anteriormente apresentados. A urgência de pesquisas e melhorias desse modelo de educação evidencia-se pelo fato de ainda não existir efetivas escolas que trabalhem nessa perspectiva de uma educação inovadora voltada para os anseios da população do campo, que preserve e respeite seus costumes e tradições, evitando assim uma educação em descompasso com seu modo de vida.

\section{Referências}

ANTONIO, C. A. Movimentos sociais, educação do campo e política educacional: adversidades para a qualidade educacional. Tempo da ciência, n.12, p.25-47, 1 semestre 2005.

BRANDÃO, C. R. A educação popular na escola cidadã. Petrópolis, RJ: Vozes, 2002.

BRANDÃO, C. A. Triângulo capital comercial, geopolítica e agroindústria, 1989. 183 f. Dissertação (Mestrado) - Centro de Desenvolvimento e Planejamento Regional da Universidade Federal de Minas Gerais, Belo Horizonte, 1989.

BRASIL. Decreto Lei $\mathrm{n}^{\circ}$ 9.394, de 20 de dezembro de 1996. Estabelece as diretrizes e bases da educação nacional.

BRASIL, Instituto Nacional de Estudos e Pesquisas Educacionais Anísio Teixeira, Censo Escolar da Educação Básica 2010, Brasília. DF. 2010. Disponível em <http://portal.inep.gov.br/basica-censo> Acesso em: 16 set. 2010.

BRASIL. Ministério da Educação. Secretaria de educação continuada, alfabetização (SECAD). Educação do Campo: diferenças mudando paradigmas. Brasília (DF), 2007. 
BRASIL. Decreto 7.352 Política de Educação do Campo e o Programa Nacional de Educação na Reforma Agrária - PRONERA. Brasília, DF, 2010.

BOGO, A. Arquitetos de sonhos. São Paulo: Editora Expressão Popular Ltda., 2003.

CALDART, R. S., Pedagogia do movimento sem terra, $3^{\text {a }}$ edição, São Paulo, Expressão Popular, 2003.

CALDART, R. S. A escola do campo em movimento In: ARROYO, M. G. CALDART, R. S. MOLINA, M. C. (org.) Por uma Educação do Campo. Petrópolis: Vozes, 2004. P. 87 a 131 .

CLEPS JUNIOR, J. Dinâmicas e estratégias do setor agroindustrial do cerrado: o caso do Triângulo Mineiro, 1998. 256 f. Tese (doutorado) - Curso de Pós Graduação em Geografia - Área de concentração em organização do espaço, Universidade Estadual Paulista "Julio de Mesquita Filho" Campos Rio Claro, 1998.

FAGUNDES, A. L.; DE DAVID C. O dinamismo na prática pedagógica da escola itinerante do MST e o ensino de Geografia. In: XIX ENCONTRO NACIONAL DE GEOGRAFIA AGRÁRIA, 19, 2009, São Paulo: Departamento de Geografia - FFLCHUSP, 2009. p. 1-17.

FERNANDES, B. M. A formação do MST no Brasil. Petrópolis: Vozes, 2000.

FERNANDES, B. M. Diretrizes de uma caminhada. In: ARROYO, M. G. CALDART, R. S. MOLINA, M. C. (org.) Por uma Educação do Campo. Petrópolis: Vozes, 2004. P. 134 a 158 .

GRZYBOWSKI, C. Caminhos e descaminhos dos movimentos sociais no campo. $2^{\text {a }}$ ed. Rio de Janeiro: FASE/ Vozes, 1987.

JESUS, I. N. Escola Família Agrícola: uma proposta de educação em desenvolvimento no campo e do campo. In: PEREIRA, J. B., COSTA E SILVA, V., PACHECO, Z. (Org.) Pedagogia Da Alternância: construindo a educação no campo. Goiânia: Brasília, Ed. da UCG/ Ed. Universa, 2006. P. 123-138.

LEITE, S. C. Escola Rural: urbanização e políticas educacionais 2 ed. São Paulo. Ed: Cortez, 2002.

MINAS GERAIS, Secretaria de Estado da Educação. Lista de escolas públicas e particulares de Minas Gerais, Belo Horizonte. MG. 2010. Disponível em <https://www.educacao.mg.gov.br/escolas/lista-de-escolas> Acesso em: 16 set. 2010.

MEURER, A. C.; DE DAVID, C. Educação no campo e escola itinerante do MST: articulação do projeto político-pedagógico com o contexto sócio-educacional. Disponível em: <http://www.ufsm.br/ce/revista> Acesso em: 14 jul. 2010.

MEURER, A. C.; DAVID, C. (Org.). Espaços-tempos de itinerância: articulações entre universidade e escola itinerante do MST. Santa Maria - RS: Ed. UFSM, 2006.

MOREIRA, M. C. Diversidade cultural e formação de professores/as: uma experiência em um assentamento rural. 2004. 186 f. Dissertação (Mestrado em Educação)-Programa de Mestrado em Educação, Universidade Federal de Uberaba, Uberaba, 2004.

MORIGI, V. Escola do MST: uma utopia em construção. Porto Alegre: Mediação, 2003.

PALADIM JÚNIOR, H. A. Educação do Campo: a territorialização e a espacialização do MST. São Paulo, SP: ANNABLUME, 2010.

PESSÔA, V. L. S. Características da modernização da agricultura e do desenvolvimento rural em Uberlândia. 1982. 164 f. Dissertação (Mestrado em Geografia)- Curso de Pós Graduação em Geografia - Área de concentração em 
organização do espaço, Universidade Estadual Paulista "Julio de Mesquita Filho" Campos Rio Claro, 1982.

PETTY, M. TOMBIM, A. VERA, R. uma alternativa em educação rural. In: WERTHEN, J. BORDEVANE, J. D. (Org.) Educação rural no terceiro mundo: experiências e novas alternativas. Tradução de Paulo Roberto Kraner e Lúcia Teresa Lessa Carregal. 2 ed. Rio de Janeiro: Paz e Terra, 1985. p.31 -63.

RIBEIRO, M. Movimento camponês trabalho e educação: liberdade, autonomia, emancipação: princípios/fins da formação humana. São Paulo, SP: Expressão Popular, 2010.

SILVA, A. C. O. Educação no campo e trabalho: um estudo das escolas municipais rurais de Uberlândia-MG. 125f. Dissertação (Mestrado em Educação), FACED-UFU, 2011.

SOUZA, J. F. Educação popular e movimentos sociais no Brasil. In: CANÁRIO, Rui. (Org.). Educação popular \& movimentos sociais. Lisboa: Educa, 2007.

SOUZA, C. L. F.. SILVA, E. B.. SOUSA, F. C. et al. Geografia e Educação do Campo: para que e quem serve a educação no campo do Estado de Goiás?. Goiânia: Editora Vieira, 2010.

SOARES, B. R. CAVALINI, M. B. PESSÔA, V. L. S. O espaço rural de Uberlândia no ano de seu centenário. Cadernos de Geografia. Uberlândia, n. 2, p 1 - 53, dez. 1988.

UBERLÂNDIA. Secretaria Municipal de Educação. Disponível em <http://www5.uberlandia.mg.gov.br > Acesso em: 16 nov. 2013.

VENDRAMINI, C. R. A escola diante do multifacetado espaço rural. Perspectiva Revista do Centro de Ciências da Educação, Florianópolis, v.21, n.1, jan./jun. 2004, p. 145-166.

Notas

\footnotetext{
${ }^{\text {i }}$ Mestrando no Programa de Pós-graduação em Geografia. Membro do Núcleo de Estudos Agrários e Territoriais- NEAT e do Laboratório de Geografia Agrária - LAGEA ricardoleyte @ yahoo.com.br

ii Professor do Instituto de Geografia e do Programa de Pós-Graduação em Geografia da Universidade Federal de Uberlândia. Membro do Núcleo de Estudos Agrários e Territoriais - NEAT e do Laboratório de Geografia Agrária - LAGEA chelotti@ig.ufu.br
}

Recebido em abril-13

Aprovado em maio-13 